\title{
Trametinib in the treatment of melanoma
}

\author{
Ramya Thota, MBBS, Douglas B. Johnson, MD, Jeffrey A. Sosman, MD \\ Departments of Medicine, Vanderbilt University Medical Center, Nashville, TN.
}

\begin{abstract}
Introduction-Aberrant Mitogen Activated Protein Kinase (MAPK) pathway signaling is a hallmark of melanoma. Mitogen/Extracellular signal-regulated Kinase (MEK) 1/2 are integral components of MAPK signaling. Several MEK inhibitors have demonstrated activity as single agents and in combination with other therapies. Trametinib was the first MEK inhibitor approved for use in treatment of advanced $B R A F^{\mathrm{V} 600}$ mutant melanoma as a single agent and in combination with BRAF inhibitor, dabrafenib.
\end{abstract}

Areas Covered-In this article, we discuss the underlying biology of MEK inhibition and its rationale in melanoma treatment with special emphasis on the clinical development of trametinib, from initial phase I studies to randomized phase II and III studies, both as monotherapy and in combination with other therapeutics. Furthermore, we briefly comment on trametinib for $N R A S$ mutant and other non-BRAF mutant subsets of melanoma.

Expert Opinion-Trametinib is a novel oral MEK inhibitor with clinical activity in $B R A F^{V 600}$ mutant metastatic melanoma alone and in combination with dabrafenib. Trametinib is currently being explored in other genetic subsets as well, particularly those with $N R A S$ mutations or atypical $B R A F$ alterations. Furthermore, to maximize efficacy and overcome acquired resistance, studies evaluating the combination of trametinib with other targeted agents and immunotherapy are underway.

\section{Keywords}

Trametinib; GSK1120212; MEK inhibitor; melanoma; BRAF; NRAS; molecularly targeted therapy

\section{Introduction:}

\subsection{Overview}

Malignant melanoma is the most aggressive of the cutaneous malignancies. For decades, the treatment options for patients with advanced disease were limited with an estimated median overall survival of less than a year [1]. However, the treatment paradigm of metastatic melanoma has changed rapidly in recent years [2].

Melanoma can be classified into distinct molecular cohorts based on the underlying genetic alterations. $B R A F^{\mathrm{V} 600}$ mutations are seen in $40-50 \%$ of all melanomas. A substitution of 
valine for glutamine at this codon (V600E) occurs in nearly $90 \%$ of all $B R A F$ mutant melanomas [3,4]. Following BRAF, NRAS mutations are frequently noted in $15-25 \%$ of all melanomas [5]. Other less common alterations include KIT mutations (1-2\%), and mutations in GNAQ and GNA11 (80-90\% of ocular melanomas) [6]. The remaining 30$35 \%$ of melanomas do not harbor recurrent alterations in these well-characterized driver genes. However, recently the NF1 mutated or deleted (a potential driver mutation) subset overall appears to represent up to $12 \%$ melanomas and is found within the $B R A F-, N R A S-, C K I T$ - melanomas. Of note, certain mutations are notably associated with specific subtypes of melanomas such as KIT mutations seen in 15-20\% of acral and mucosal melanoma [7]. Likewise, GNAQ and GNA11 mutations are seen in the large majority of uveal melanomas [8,9].

Among several MEK inhibitors in clinical development, Trametinib (GSK1120212, Mekinist $^{\mathrm{TM}}$, GlaxoSmithKline, London) is the only MEK 1/2 inhibitor approved by FDA either as monotherapy or in combination with dabrafenib for the treatment of unresectable or metastatic $B R A F^{\mathrm{V} 600 \mathrm{E}}$ or $B R A F^{\mathrm{V} 600 \mathrm{~K}}$ mutant melanoma.

\subsection{Overview of the market}

Improved understanding of genetic and molecular basis of melanoma has revolutionized treatment options for advanced melanoma leading to the approval of six new drugs in past 4 years including $\mathrm{T}$ cell regulatory immune therapies including the human anti-cytotoxic $\mathrm{T}$ lymphocyte antigen-4 (CTLA4) monoclonal antibodies (ipilimumab) [10], anti-programmed death-1 (PD-1) antibodies (pembrolizumab, nivolumab) [11] and targeted therapies against mitogen-activated protein kinase (MAPK) pathway including BRAF inhibitors (vemurafenib [12], dabrafenib [13]), MEK inhibitor (trametinib) [14] and recently the combination of BRAF and MEK inhibitors (dabrafenib with trametinib) [15]. In spite of these advances, the treatment of melanoma remains challenging in terms of treatment selection and appropriate sequencing of these drugs to achieve optimal outcomes.

In particular, there has been remarkable progress for the $B R A F$ mutant subset of melanoma with the development of the selective BRAF and MEK inhibitors. BRAF inhibitors alone produce response rates in the range of $40-50 \%$ with a median progression free survival (PFS) of 6-7 months $[12,13]$. However, due to paradoxical activation of the MAPK pathway, some patients develop secondary cutaneous malignancies and almost all eventually develop acquired resistance via compensatory reactivation of the MAPK pathway or parallel signaling pathways. These resistance mechanisms include aberrant $B R A F$ splicing, increase in $B R A F$ copy number gains, mutations in $N R A S$ or $M E K^{1 / 2}, C O T$ overexpression, growth factor up regulation, and alterations in the PI3K/AKT pathway [16,17].

Trametinib (GSK1120212, JTP 74057, Mekinist ${ }^{\mathrm{TM}}$, GlaxoSmithKline, London), an oral MEK inhibitor also has activity in the $B R A F^{V 600}$ cohort. Trametinib demonstrated significantly improved response rates (22\% vs. $8 \%$ ) median PFS (4.8 months vs. 1.5 months) and 6 month OS ( $81 \%$ vs. $67 \%$ ) compared with chemotherapy in a phase III clinical trial [14]. This single agent activity appears slightly inferior to single agent BRAF inhibition, and has led to somewhat infrequent use as monotherapy. By contrast, the combination of BRAF with MEK inhibitors resulted in more frequent responses and improved progression free 
survival and overall survival compared to BRAF inhibitors alone [15,18,19]. Although the initial responses are more prolonged with the combination of BRAF and MEK inhibition (approximately 9-11 months), acquired resistance still occurs and usually involves MAPK reactivation $[20,21]$. The detailed mechanisms to overcome the resistance by complete blockade of the MAPK pathway are still being elucidated.

In addition, there is encouraging early clinical activity of other MEK inhibitors (binimetinib, RO4987655) alone and in combination with CDK4/6 inhibitors (palbociclib, LEE011) [22] and also emerging evidence of synergistic activity of trametinib in combination with metformin in NRAS mutant melanoma [23]. Furthermore, due to early signs of efficacy in $R A S$ mutated tumors, presently the role of MEK inhibition is being actively explored in other $R A S$ mutated tumors like non-small cell lung cancer, pancreatic, and hepatobiliary cancers.

\subsection{Chemistry and Pharmacokinetics}

Trametinib dimethyl sulfoxide $\left(\mathrm{C}_{26} \mathrm{H}_{23} \mathrm{FIN}_{5} \mathrm{O}_{4}\right)$ is a highly potent reversible allosteric inhibitor of MEK 1 and 2 inhibitor with a molecular weight of $615.39 \mathrm{~g} / \mathrm{mol}$ [24 25]. It is rapidly absorbed when orally administered. The peak plasma concentration ( $\mathrm{T}$ max) occurs in 1.5 hours with an absolute bioavailability of $72 \%$ [24]. In patients receiving a single oral dose of trametinib $2 \mathrm{mg}$ per day, the area under the curve (AUC) and mean peak plasma concentrations (Cmax) of trametinib is $370 \mathrm{ngh} / \mathrm{mL}$ and $22.2 \mathrm{ng} / \mathrm{ml}$ respectively [26].

The systemic exposure to trametinib was decreased when the drug was administered with a high-fat meal. Trametinib dose administered with a high fat meal decreased Cmax by $70 \%$ and AUC by $24 \%$ also prolonged T max to 5.5 hours compared to the fasted state, which may decrease the drug effect [24]. Hence it is recommended that trametinib be administered on an empty stomach ( 1 hour before or 2 hours after food) [27]. Trametinib is $97 \%$ bound to human plasma proteins, independent of its concentration. After a single dose of trametinib 2 $\mathrm{mg}$ in patients, the apparent volume of distribution $(\mathrm{Vd})$ was $214 \mathrm{~L}$.

The majority $(80 \%)$ of a radiolabelled dose of trametinib was recovered in the feces and less than $20 \%$ of the dose was recovered in the urine. Less than $0.1 \%$ of the drug is eliminated as unchanged drug. The mean apparent plasma terminal elimination half-life of trametinib was 3.8 to 4.8 days, following a single oral dose of $2 \mathrm{mg}$ in patients. The mean apparent clearance of trametinib is $4.9 \mathrm{~L} / \mathrm{h}$. The trough concentrations ranged from a mean of 10.0 to $18.9 \mathrm{ng} / \mathrm{mL}[24]$.

\subsection{Drug-Drug interactions}

Trametinib is metabolized by non-cytochrome (CYP450) mediated mechanisms mainly involving deacetylation via hydrolytic enzymes alone or in combination with glucuronidation, therefore has very limited drug-drug interactions reported. At clinically relevant concentrations, trametinib is not a substrate for CYP enzymes, apical efflux transporters, P-glycoprotein, breast cancer resistance protein (BCRP), hepatic uptake transporters organic anion transporting polypeptide OATP1B1 and OATP1B3 [24]. 
At clinical concentrations, trametinib may inhibit CYP2C8 and induce CYP3A4, according to in vitro studies [24]; therefore, co-administration of the drug with CYP3A 4 and CYP2C8 substrates or substrates largely metabolized by these enzymes should be avoided [24]. It is known that dabrafenib is a substrate of both CYP2C8 and CYP3A4. The trametinib at 2mg dose when administered along with dabrafenib $150 \mathrm{mg}$ twice a day resulted in a $23 \%$ increase in the AUC of dabrafenib without any change in the AUC of trametinib when compared with either drug alone suggesting minor inhibitory effect of trametinib on clearance of dabrafenib [15]. However, as dabrafenib is not routinely administered at the maximum tolerated dose the final recommended daily dosing of the combination remains the same $[13,28]$.

\subsection{Pharmacodynamics}

Trametinib is an allosteric kinase inhibitor of both isoforms of MEK. Trametinib directly binds to unphosphorylated MEK1 and MEK2 and inhibits their kinase activities with a halfmaximum inhibitory concentration (IC50) of 0.7-0.9 nmol/L [29]. It selectively inhibits MEK 1 and 2 without any inhibition noted when tested against more than 98 other kinases [30]. Further, it reversibly inhibits the RAF mediated phosphorylation thereby suppressing the downstream ERK signaling activity [31]. Inhibition of phosphorylated ERK, Ki-67 and increase in p27 were used as biomarkers of MEK inhibitor activity.

Trametinib induced rapid and sustained dephosphorylation of phosphorylated MEK in $B R A F^{\mathrm{V} 600 \mathrm{E}}$ melanoma, HT-29 colon and other cancer cell lines, along with sustained tumor growth inhibition in xenograft tumors in nude mice [30]. At standard dosing of $2 \mathrm{mg}$ daily, trametinib produced dose-dependent changes in tumor biomarkers with a median change of $30 \%$ inhibition of phosphorylated ERK, 54\% inhibition of Ki67 and an 83\% increase of p27 [32].

Compared to other MEK inhibitors, trametinib had varied MEK binding affinity. Trametinib has lower binding affinity for MEK1/2 (IC50 =0.7nM) than cobimetinib $($ IC50 = $4.2 \mathrm{nM})$ [33]. Likewise, trametinib has also shown differential high sensitivity against BRAF (IC50 = $0.3-0.85 \mathrm{nM}$ ) and NRAS mutant cell lines (IC50 $=0.36-0.63 \mathrm{nM}$ ), as compared with wild type $(\mathrm{IC} 50=0.31-10 \mathrm{nM})$ melanoma cell lines [34].

\section{Clinical Activity}

\subsection{Preclinical data}

In cell lines and xenograft models of RAS mutated tumors, MEK was identified as potential therapeutic target based on the complete suppression of tumor growth in BRAF mutant xenografts and partial inhibition in RAS mutant tumors with use of selective MEK inhibitors [35]. Despite strong preclinical evidence, first and second generation MEK inhibitors such as CI-1040 and PD-0325901 either failed to show clinical activity or caused severe toxicities due to their narrow therapeutic window and simultaneous inhibition of MEK dependent nontumor human tissues [36, 37]. Further enzymatic and cellular studies led to development of trametinib. Trametinib is a potent selective ATP noncompetitive allosteric inhibitor of MEK 1 and 2 kinases that prevents Raf-dependent phosphorylation of MEK and thus MAPK 
pathway activation. In vitro, trametinib suppressed the tumor growth and had a favorable pharmacokinetic profile with a long circulating half-life and sustained suppression of pERK1/2 for more than 24 hours with greater antitumor effect among mutant BRAF or RAS tumors [31]. Based on this intriguing preclinical data, further clinical development of trametinib was undertaken.

\subsection{Phase I trials}

2.1.1 Trametinib Monotherapy-In a Phase I study, 206 patients with advanced solid tumors (including melanoma, non-small-cell lung cancer, colorectal cancer, and pancreatic cancers) were enrolled and treated with single agent trametinib [26]. Although the maximum tolerated dose in the study was $3 \mathrm{mg}, 2 \mathrm{mg}$ once daily was associated with better safety, tolerability and clinical activity and was the final recommended phase 2 dose. The doselimiting toxicities (DLTs) were rash, diarrhea and central serous retinopathy. The common adverse events (any grade/grade 3 and 4 ) reported were skin rash (80/8\%), diarrhea (42/ $<1 \%)$, peripheral edema $(33 /<1 \%)$, fatigue $(29 / 4 \%)$, and nausea $(28 / 0 \%)$. Other less common but notable side effects included ocular toxicities such as central retinal vein occlusion $(15 /<1 \%)$ and decreased cardiac ejection fraction $(8 / 0 \%)$. No cutaneous squamous cell carcinomas were observed. Among all patients, objective tumor responses were noted in $10 \%$ with majority of responses in $B R A F$ mutant melanomas.

Among melanoma patients, the response rates were significantly better in $B R A F$ mutant melanoma (33\%) compared to $B R A F$ wild type tumors (10\%) [32]. Although no objective responses were noted in NRAS mutant or uveal melanoma patients, approximately $27 \%$ (2 of 7) and 12\% (2 of 16) had stable disease respectively [32].

2.1.2 Trametinib with dabrafenib-Flaherty and colleagues conducted a phase I/II study of 247 patients with metastatic $B R A F^{V 600}$ mutated melanoma patients. The safety and pharmacokinetic activity was tested in first 85 patients (Phase I part) with variable doses of oral dabrafenib (75 or $150 \mathrm{mg}$ twice daily) and trametinib (1, 1.5, or $2 \mathrm{mg}$ daily) [15]. See section 2.2.2 for more details.

2.1.3 Trametinib in other malignancies-The efficacy of MEK inhibition has been explored in other tumors as well. In pancreatic adenocarcinoma, the clinical benefit rate was $50 \%$ including objective partial responses in $8 \%$ and some degree of tumor regression in $42 \%$ [26]. In NSCLC, 2 of 30 patients had partial responses. Temporary stabilization of tumor growth was also demonstrated occasionally in colorectal adenocarcinoma and other cancers [26]. Additionally, preclinical studies in human leukemic cells and primary mouse leukemia with NRAS mutations showed that trametinib reduced cell proliferation and prolonged survival. An early phase I trial showed promising clinical activity of trametinib in NRAS or KRAS mutant acute myeloid leukemia (AML) [38,39].

Based on the promising synergistic preclinical data of combined inhibition of MEK and PI3K/AKT/mTOR or cell cycle regulatory pathways, various early phase clinical trials of trametinib in combination with pan PI3K or AKT or mTOR or CDK inhibitors are currently ongoing [40,41]. In a phase $1 \mathrm{~b}$ dose escalation study of 113 patients with RAS or BRAF mutant advanced solid tumors, the combination of trametinib with pan PIK3 inhibitor, 
buparlisib (BKM120) is well tolerated and showed favorable activity especially in KRAS mutant ovarian cancer patients [42]. In contrast, both the combinations of trametinib with AKT inhibitor (afuresertib) or mTOR inhibitor (everolimus) were poorly tolerated and lacked clinical efficacy $[43,44]$. Other combinations such as gemcitabine were well tolerated in phase I setting but failed to show therapeutic efficacy in phase II studies [45,46].

\subsection{Phase II trials}

2.2.1 Trametinib Monotherapy-In a phase II open label study of metastatic $B R A F^{\mathrm{V} 600}$ mutant melanoma treated with trametinib, the response rates and progression free survival were significantly better for BRAF inhibitor naïve patients. While patients with prior BRAF inhibitor therapy $(\mathrm{N}=40)$ had no responses, $25 \%$ of BRAF inhibitor-naïve patients had objective responses $(\mathrm{N}=57)$. Likewise the median progression free survival in BRAF inhibitor naïve patients was 4 months compared to 1.8 months in those with prior BRAF inhibitor treatment. These results establish lack of efficacy of MEK inhibition after progression on BRAF inhibitor therapy [47].

2.2.2 Trametinib and Dabrafenib-A phase II trial randomized 162 patients 1:1:1 to either combination therapy with dabrafenib and trametinib (150/1 or 150/2 mg) or dabrafenib monotherapy. The patients were allowed to cross over to combination (150/2) upon progression. The combination of trametinib with dabrafenib resulted in reduced incidence of cutaneous squamous-cell carcinoma (7\% vs. 19\%), but high rates of pyrexia (71\% vs. $26 \%$ ) compared to dabrafenib alone. Also, the combination group had higher response rates ( $76 \%$ vs. $54 \% ; \mathrm{P}=0.03$ ) and prolonged median progression-free survival 9.4 vs. 5.8 months, $\mathrm{HR}=0.39 ; \mathrm{P}<0.001)[15]$.

In this study the efficacy of combination therapy in patients who progressed on prior BRAF inhibitor therapy was evaluated. The patients who received dabrafenib for more than 6 months had better response rates ( $26 \%$ vs.0\%) and improved PFS (3.9 vs. 1.8 months; $\mathrm{P}=0.02$ ) with the combination compared with those treated $<6$ months of BRAF inhibitor therapy [48]. Thus combination treatment has modest clinical efficacy in patients with BRAF inhibitor-resistant melanoma and can be considered in patients with prior prolonged response to BRAF inhibition.

\subsection{Phase III trials}

2.3.1 Trametinib Monotherapy: METRIC study-In the open label phase III METRIC study, a total of 322 patients with metastatic $B R A F^{\mathrm{V} 600 \mathrm{E}}$ or $B R A F^{\mathrm{V} 600 \mathrm{~K}}$ mutated melanoma were randomized to receive either trametinib $2 \mathrm{mg}$ once daily or chemotherapy (dacarbazine or paclitaxel). Trametinib significantly improved response rates and progression free survival (PFS) compared to chemotherapy (22\% vs. $8 \%$ and 4.8 months vs. 1.5 months). Although nearly half of patients crossed over from chemotherapy to trametinib at progression, improved 6 month overall survival (OS) was noted with trametinib (81\% vs. $67 \%)[14]$.

2.3.2 Trametinib and Dabrafenib-In the phase III COMBI-d trial, 423 patients with newly diagnosed advanced $B R A F^{\mathrm{V} 600 \mathrm{E}}$ or $B R A F^{\mathrm{V} 600 \mathrm{~K}}$ mutated melanoma were treated 
with either dabrafenib plus trametinib or to dabrafenib plus placebo. The progression-free survival was significantly prolonged with the combination compared with dabrafenib alone (9.3 versus 8.8 months). The objective response rate was also significantly improved (67 versus 51 percent) with the combination [18]. Interestingly, the combination treatment group had decreased incidence of cutaneous squamous cell carcinoma (2\% vs. $9 \%$ ) and more frequent pyrexia (51\% vs. $28 \%$ ) chills ( $28 \%$ vs. $16 \%$ ), diarrhea ( $24 \%$ vs. $14 \%)$ and hypertension ( $22 \%$ vs. $14 \%$ ) compared to dabrafenib alone group. Dose interruptions were significantly more frequent with the combination, mainly due to fevers and chills [18].

Another phase III study compared dabrafenib plus trametinib with vemurafenib (COMBI-V) and found significantly improved outcomes with the combination (1 year OS $72 \%$ vs. 65\%; $\mathrm{HR}=0.69 ; \mathrm{P}=0.005$ and median $\mathrm{PFS} 11.4$ vs. 7.3 months; $\mathrm{HR}=0.56 ; \mathrm{P}<0.001$, respectively). Likewise, the objective response rate was also superior in the combination group (64\% vs. $51 \% ; \mathrm{P}<0.001)$. The incidence of adverse events was similar in both groups but cutaneous squamous-cell carcinoma and keratoacanthoma were significantly less common in the combination group compared with vemurafenib group (1\% vs. 18\%) [19].

\section{Trametinib in NRAS Mutant Melanoma}

$N R A S$ mutant melanomas are the second most common molecular cohort representing nearly $15-25 \%$ of all melanomas [49]. Unlike mutant BRAF, mutant NRAS activates downstream CRAF, MEK, and ERK in the MAP kinase pathway bypassing BRAF. Therefore selective BRAF inhibitors are unlikely to have any effect on the NRAS mutant melanomas [5].

MEK inhibition, by contrast, may have a role in treating $N R A S$ mutant melanoma. Trametinib was associated with stable disease in 2 of 7 patients treated in the phase I clinical trial [32]. In a phase II study of binimetinib (MEK162), 6 of 30 patients (20\%) had partial responses in NRAS mutant melanoma [50].

Recently, in a phase I PACMEL study, the combination of trametinib with paclitaxel in BRAF wild type melanoma demonstrated a $40 \%$ partial response rate and median OS of 14 months [51]. Notably, 4 of 6 patients with $N R A S$-mutant melanoma experienced a response.

In addition to alterations in the MAPK pathway, cell cycle checkpoint dysregulation is also frequently noted in melanoma. In a phase $1 \mathrm{~b} / 2$ study of the combination of binimetinib with selective CDK4/6 inhibitor LEE011 in NRAS mutant melanoma, 7 of 21 patients had partial responses $(33 \%)$ and $>80 \%$ of patients had some degree of tumor regression [22]. Currently early phase trials evaluating the combination of trametinib with the CDK4/6 inhibitor palbociclib are also underway.

Furthermore, strong preclinical evidence suggests dual inhibition of PI3K/AKT/mTOR pathway along with MAPK pathway is important in NRAS mutant melanoma [52]. However, simultaneous inhibition of both the key pathways might be clinically challenging [53]. Recently, the combination of trametinib with metformin (which indirectly inhibits the $\mathrm{PI} 3 \mathrm{~K} / \mathrm{AKT} / \mathrm{mTOR}$ pathway) showed synergistic activity in NRAS mutant cell lines as well as in xenograft tumor models [23]. Combined inhibition of MEK and ERK also appears to 
be a promising strategy in $N R A S$-mutant pre-clinical models [54]. Rationally designed targeted therapies combinations including trametinib may play a major role in the therapy of NRAS mutant melanoma in the future.

\section{Trametinib in $B R A F^{6000 / N R A S ~ W i l d ~ T y p e ~ M e l a n o m a ~}$}

Despite rapid developments in $B R A F$ mutant melanoma, no targeted therapy options exist for patients with $B R A F N R A S$ wild type melanoma. Preclinical evidence suggests activity of trametinib in $B R A F / N R A S$ wild type melanoma cell lines with or without loss of $N F 1$ ( $12 \%$ of melanomas) $[55,56]$. In the early phase I study, trametinib monotherapy resulted in partial responses (10\%) in wild type melanoma patients as well [32]. Intriguingly several responses in patients with atypical $B R A F$ mutations have been noted. Specifically, preclinical data, early trametinib studies, and a retrospective series the uncommon $B R A F$ K601E and L597 mutations are sensitive to trametinib [32,47,57,58]. A phase II study of trametinib in patients with atypical $B R A F$ mutations and fusions is now ongoing.

Although trametinib monotherapy may play a role in some subsets (e.g. atypical $B R A F$ mutations), combinatorial strategies will likely be needed to prevent compensatory upregulation of the MAPK and other signaling pathways in BRAF/NRAS WT melanoma.

\section{Other MEK inhibitors in Melanoma}

Binimetinib (MEK162) has shown activity in early phase II study in NRAS mutant melanoma with a $20 \%$ partial response rate [50]. The combination of cobimetinib with vemurafenib showed prolonged survival in $B R A F^{\mathrm{V} 600}$-mutated metastatic melanoma although associated with slightly increased risk of toxicity [59]. In a randomized phase II study of 98 patients, selumetinib showed improved progression free survival compared to temozolomide in metastatic uveal melanoma [60]. Other selective MEK inhibitors with preferential affinity for either $B R A F$ or $R A S$ mutant malignancies are also being developed [61].

\section{Adverse Events}

\subsection{Trametinib monotherapy}

In the randomized phase III METRIC study, trametinib was generally well tolerated; with frequent toxicities being skin rash, diarrhea, peripheral edema and fatigue [14]. The adverse events (AE) from trametinib led to dose interruptions in $35 \%$ of patients and to dose reductions in $27 \%$ of patients. Trametinib was discontinued in 2 patients due to treatmentrelated cardiac adverse events (less than 1\%) [14]. Trametinib monotherapy toxicities are listed in Table 2.

Cutaneous toxicities were the most common side effects $(76 \%)$ noted with trametinib similar to other MEK inhibitors, primarily including rash in 57\% (grade $3 / 4$ in $8 \%$ ) and acneiform dermatitis in 19\% (grade 3 in 1\%). Unlike with BRAF inhibitors, no cutaneous squamouscell carcinomas or hyper-proliferative skin lesions were observed with trametinib [14]. 
Ocular toxicities were rare (all grades 9\%); most commonly blurry vision (4\%) and central serous retinopathy (grade 3 in $<1 \%$ ). There were no reported retinal-vein occlusions.

Diarrhea (43\%) was common and usually mild (grade 2 in $6 \%$ and no grade 3 or 4 ), as was fatigue (all grades $26 \%$; grade 3 in $4 \%$ ) and peripheral edema (26\% and grade 3 in 1\%). Hypertension was reported in 15\% of patients (grade 3 in 12\%). Cardiac adverse events reported were decreased ejection fraction or ventricular dysfunction (7\%). Serious grade 3 cardiac-related events occurred in $<1 \%$ ( 2 patients) and led to permanent discontinuation of the study drug. Overall, Trametinib appeared to have a favorable impact on patient-reported functional capacity and quality of life as well [62].

\subsection{Trametinib and dabrafenib}

The combination treatment is reasonably well-tolerated associated with a distinct set of side effects compared to trametinib or dabrafenib monotherapy. The cutaneous toxic effects related to BRAF inhibition from paradoxical MAPK activation were less frequent with concomitant MEK inhibition due to more complete blockade of the MAPK pathway [63]. However, the adverse events related to MEK inhibition such as hypertension, peripheral edema, cardiac and ocular toxicities were relatively more frequent. (Table 3)

Importantly, the incidence of cutaneous toxicity in terms of rash (22-27\%), squamous-cell carcinoma (1-7\%), or hyperproliferative lesion such as keratocanthoma (4-12\%) was significantly less frequent. Also there is a significant delay in onset of cutaneous AEs compared with those on BRAF inhibitor monotherapy $[15,18,19]$.

Pyrexia (51-71\%) and chills (30-58\%) were more common with combination treatment mainly due to dabrafenib. Due to pyrexia and chills, $58 \%$ of patients experienced dose reductions although reescalation was possible in $>90 \%$ of these [15]. Overall, patients in the combination arm received treatment for longer time compared to dabrafenib alone (11 vs. 6 months) in the phase I/II trial [15]. The clinic-pathological factors associated with onset of pyrexia due to combination of dabrafenib and trametinib were evaluated in a retrospective study and noted no association with age, sex, disease burden, response, and progression-free or overall survival. Steroids were effective in treating these pyrexia episodes and allow dose re-escalation [64].

Ocular and cardiac adverse events were rare (1-2\% and 4-9\%) rare but notable for grade 3 toxicities such as hypertension (12\%), decreased ejection fraction $(0-4 \%)$ and chorioretinopathy (0-2\%). Other common toxicities that were more frequent with combination therapy included fatigue (35-53\%), nausea (30-44\%), vomiting (29-40\%), diarrhea (24-36\%), and arthralgia (24-27\%).

\section{Conclusions:}

Trametinib extends progression-free and overall survival in patients with advanced malignant melanoma. The combination of trametinib with dabrafenib delays the onset of resistance and results in higher response rates, prolonged PFS and OS compared to BRAF inhibitors alone. Due to more complete abrogation of MAPK pathway, the incidence of 
cutaneous toxicities is reduced as well. Recent randomized phase III studies have established this combination as the standard first-line targeted therapy options for patients with $B R A F^{V 600}$ mutant melanoma. Based on the preclinical and preliminary clinical evidence, currently trametinib is being explored in other subsets of melanoma and other malignancies as well.

Improved understanding of predictive biomarkers of response and resistance are needed to identify appropriate patients most likely to benefit from MEK inhibitor based regimens. Furthermore, rational therapy partners have been identified and are being evaluated in ongoing clinical trials. The most effective approach is still being elucidated but trametinib will likely play a major role in future targeted strategies.

\section{Expert Opinion}

Trametinib is the first FDA approved MEK inhibitor for the treatment of $B R A F^{V 600}$ mutant metastatic melanoma as single agent and in combination with dabrafenib. We rarely use trametinib monotherapy except in the rare patient that cannot tolerate combination therapy or BRAF inhibitor monotherapy. The combination of dabrafenib with trametinib, conversely, has demonstrated superior clinical outcomes compared to BRAF inhibitor monotherapy. This regimen has now emerged as the standard of care first-line treatment for patients with $B R A F$-mutant metastatic melanoma. Both the combination of BRAF and MEK inhibitors along with immune therapies has revolutionized the treatment of malignant melanoma with significant tumor responses and prolonged disease remissions.

Trametinib has not been directly compared with other MEK inhibitors but certain MEK inhibitors reportedly have preferential activity for specific tumor types. While trametinib and cobimetinib seem to have more activity in BRAF mutant melanomas, binimetinib has shown more promising activity in $N R A S$ mutant melanoma. Other MEK inhibitors such as GDC-0623 and CH4987655 may have better efficacy in RAS mutant tumors by blocking feedback activation of MEK by $B R A F$ wild type tumors $[61,65]$. Likewise, in a randomized phase II study of 98 patients, selumetinib showed improved progression free survival compared to temozolomide in metastatic uveal melanoma; the efficacy of trametinib in this setting is still being elucidated.

Unlike $B R A F^{V 600}$ mutant melanoma, targeted treatment options for non- $B R A F$ mutant melanoma including those with $N R A S$ mutations, atypical $B R A F$ alterations, and deletions of $N F 1$ are limited. Preclinical and early clinical trials suggest sensitivity of trametinib to atypical $B R A F$ mutations (non-V600) and $N R A S$ mutant melanoma. Currently early phase I/II trials of trametinib in combination with AKT or CDK4/6 inhibitors in $B R A F$ wild type metastatic melanoma are ongoing. A detailed list of ongoing clinical trials of trametinib in melanoma are listed in Table 4 below.

Furthermore, role of trametinib in the treatment of other $R A S / R A F$ mutated nonmelanomatous malignancies such as pancreatic cancer, NSCLC, colon cancer and acute leukemia are being explored. $B R A F$ mutations were noted in $15 \%$ of cholangiocarcinoma patients and MEK inhibitors have never been explored in these tumors but Loaiza-Bonilla 
and colleagues reported a patient with refractory cholangiocarcinoma with excellent response with combination therapy with trametinib and dabrafenib [66].

When discussing melanoma therapies, the rapid and promising developments in immunotherapy cannot be ignored. While combined BRAF/MEK regimens have induced higher response rates, their use is limited to $B R A F$ mutant melanoma. However, the immune based therapies including immune checkpoint inhibitors, anti-PD-1/PD-L1 (programmed death-1/ligand) receptor antibodies have shown efficacy irrespective of the underlying oncogenic driver mutation. Although, anti-PD-1 has demonstrated relatively lower response rates $(25-40 \%)$, they have a very tolerable side effect profile, and more importantly, have induced sustained long-term responses. Currently ipilimumab, pembrolizumab, and nivolumab are FDA approved immune therapies for the treatment of metastatic melanoma. In addition, in a phase I study of 53 patients, the combination of ipilimumab with nivolumab resulted in rapid durable tumor regressions ( $80 \%$ or more) irrespective of $B R A F$ mutations status in around $40 \%$ of patients but severe grade 3 or 4 adverse events were noted in $62 \%$ of patients [67].

Combination strategies of immune therapy and targeted therapy are being explored aiming for deeper and durable responses [68]. The overall impact of MEK inhibition on immune response is not well defined due to conflicting preclinical data. One study suggests MEK inhibitors inhibit T cell function and suppress PD-L1 expression [69] and another implicates negative impact of MEK inhibition on the immune system through reduced cytokine production and impaired $\mathrm{T}$ cell and dendritic function [70].

Appropriate sequencing or combination of these targeted and immune agents in the treatment of $B R A F$ mutant melanoma remains elusive. In a phase I study of combination of ipilimumab with BRAF inhibitor vemurafenib resulted in severe hepatotoxicity leading to early closure of the study [71]. The combination of ipilimumab with combined dabrafenib and trametinib also had severe toxicities although so far dabrafenib and ipilimumab appears tolerable [72]. Currently combinations of anti PD-1/PDL-1 with trametinib +/- dabrafenib are ongoing. In the future, rationally selected newer combinational strategies will be pursued (Table 4).

In summary, trametinib in combination with dabrafenib has been a remarkable advancement in the treatment of $B R A F$ mutant melanoma and has future potential in other non- $B R A F$ mutant melanomas as well. With the recent dramatic change in the treatment landscape of metastatic melanoma, the future use of trametinib may be undermined amidst future development of other MEK inhibitors and immune therapies. Better understanding of the molecular mechanisms of resistance via aberrantly activated signaling pathways will facilitate rational development of future combinational therapies.

\section{Financial and competing interests disclosure}

DBJ has received funding from the NIH (K12 CA 0906525). JAS serves on advisory boards for GlaxoSmithKline and Bristol Myers Squibb. The authors have no other relevant affiliations or financial involvement with any organization or entity with a financial interest in or financial conflict with the subject matter or materials discussed in the manuscript. This includes employment, consultancies, honoraria, stock ownership or options, expert testimony, grants or patents received or pending, or royalties. 


\section{References:}

1. Balch CM, Soong SJ, Gershenwald JE, et al.: Prognostic factors analysis of 17,600 melanoma patients: validation of the American Joint Committee on Cancer melanoma staging system. J Clin Oncol 19:3622-34, 2001 [PubMed: 11504744]

2. Curti BD: Rapid evolution of combination therapy in melanoma. N Engl J Med 371:1929-30, 2014 [PubMed: 25390744]

3. Lovly CM, Dahlman KB, Fohn LE, et al.: Routine multiplex mutational profiling of melanomas enables enrollment in genotype-driven therapeutic trials. PLoS One 7:e35309, 2012 [PubMed: 22536370]

4. Curtin JA, Fridlyand J, Kageshita T, et al.: Distinct sets of genetic alterations in melanoma. N Engl J Med 353:2135-47, 2005 [PubMed: 16291983]

5. Fedorenko IV, Gibney GT, Smalley KS: NRAS mutant melanoma: biological behavior and future strategies for therapeutic management. Oncogene 32:3009-18, 2013 [PubMed: 23069660]

6. Shtivelman E, Davies MQ, Hwu P, et al.: Pathways and therapeutic targets in melanoma. Oncotarget 5:1701-52, 2014 [PubMed: 24743024]

7. Curtin JA, Busam K, Pinkel D, et al.: Somatic activation of KIT in distinct subtypes of melanoma. J Clin Oncol 24:4340-6, 2006 [PubMed: 16908931]

8. Shoushtari AN, Carvajal RD: GNAQ and GNA11 mutations in uveal melanoma. Melanoma Res 24:525-34, 2014 [PubMed: 25304237]

9. Van Raamsdonk CD, Bezrookove V, Green G, et al.: Frequent somatic mutations of GNAQ in uveal melanoma and blue naevi. Nature 457:599-602, 2009 [PubMed: 19078957]

10. Hodi FS, O'Day SJ, McDermott DF, et al.: Improved survival with ipilimumab in patients with metastatic melanoma. N Engl J Med 363:711-23, 2010 [PubMed: 20525992]

11. Robert C, Ribas A, Wolchok JD, et al.: Anti-programmed-death-receptor-1 treatment with pembrolizumab in ipilimumab-refractory advanced melanoma: a randomised dose-comparison cohort of a phase 1 trial. Lancet 384:1109-17, 2014 [PubMed: 25034862]

12. Chapman PB, Hauschild A, Robert C, et al.: Improved survival with vemurafenib in melanoma with BRAF V600E mutation. N Engl J Med 364:2507-16, 2011 [PubMed: 21639808]

13. Hauschild A, Grob JJ, Demidov LV, et al.: Dabrafenib in BRAF-mutated metastatic melanoma: a multicentre, open-label, phase 3 randomised controlled trial. Lancet 380:358-65, 2012 [PubMed: 22735384]

14. Flaherty KT, Robert C, Hersey P, et al.: Improved survival with MEK inhibition in BRAF-mutated melanoma. N Engl J Med 367:107-14, 2012 [PubMed: 22663011] •• Improved overall survival in BRAF-mutant melanoma with trametinib.

15. Flaherty KT, Infante JR, Daud A, et al.: Combined BRAF and MEK inhibition in melanoma with BRAF V600 mutations. N Engl J Med 367:1694-703, 2012 [PubMed: 23020132] •• First clinical trial that successfully combined targeted therapies in melanoma.

16. Rizos H, Menzies AM, Pupo GM, et al.: BRAF inhibitor resistance mechanisms in metastatic melanoma: spectrum and clinical impact. Clin Cancer Res 20:1965-77, 2014 [PubMed: 24463458]

17. Shi H, Hugo W, Kong X, et al.: Acquired resistance and clonal evolution in melanoma during BRAF inhibitor therapy. Cancer Discov 4:80-93, 2014 [PubMed: 24265155]

18. Long GV, Stroyakovskiy D, Gogas H, et al.: Combined BRAF and MEK inhibition versus BRAF inhibition alone in melanoma. N Engl J Med 371:1877-88, 2014 [PubMed: 25265492] ** A randomized phase III trial showing superior efficacy of dabrafenib/trametinib compared to dabrafenib in patients with BRAFV600 mutant melanoma

19. Robert C, Karaszewska B, Schachter J, et al.: Improved overall survival in melanoma with combined dabrafenib and trametinib. N Engl J Med 372:30-9, 2015 [PubMed: 25399551]

20. Menzies AM, Haydu LE, Carlino MS, et al.: Inter- and intra-patient heterogeneity of response and progression to targeted therapy in metastatic melanoma. PLoS One 9:e85004, 2014 [PubMed: 24400126] 
21. Long GV, Fung C, Menzies AM, et al.: Increased MAPK reactivation in early resistance to dabrafenib/trametinib combination therapy of BRAF-mutant metastatic melanoma. Nat Commun 5:5694, 2014 [PubMed: 25452114]

22. Sosman JA K M, Lolkema MPJK, et al.: A phase 1b/2 study of LEE011 in combination with binimetinib (MEK162) in patients with NRAS-mutant melanoma: Early encouraging clinical activity. . J Clin Oncol, 32 (5s) (2014) suppl; abstract 9009

23. Vujic I, Sanlorenzo M, Posch C, et al.: Metformin and trametinib have synergistic effects on cell viability and tumor growth in NRAS mutant cancer. Oncotarget, 2014

24. Mekinist [package insert]. Research Triangle Park, NC: GlaxoSmithKline; 12014.

25. Salama AK, Kim KB: Trametinib (GSK1120212) in the treatment of melanoma. Expert Opin Pharmacother 14:619-27, 2013 [PubMed: 23432625]

26. Infante JR, Fecher LA, Falchook GS, et al.: Safety, pharmacokinetic, pharmacodynamic, and efficacy data for the oral MEK inhibitor trametinib: a phase 1 dose-escalation trial. Lancet Oncol 13:773-81, 2012 [PubMed: 22805291] • The first in human phase I clinical trial of trametinib

27. Cox DS, Papadopoulos K, Fang L, et al.: Evaluation of the effects of food on the single-dose pharmacokinetics of trametinib, a first-in-class MEK inhibitor, in patients with cancer. J Clin Pharmacol 53:946-54, 2013 [PubMed: 23893461]

28. Tafinlar (dabrafenib) [package insert]. Research Triangle Park, NC: GlaxoSmithKline; 12014.

29. Yoshida T, Kakegawa J, Yamaguchi T, et al.: Identification and characterization of a novel chemotype MEK inhibitor able to alter the phosphorylation state of MEK1/2. Oncotarget 3:153345, 2012 [PubMed: 23237773]

30. Yamaguchi T, Kakefuda R, Tajima N, et al.: Antitumor activities of JTP-74057 (GSK1120212), a novel MEK1/2 inhibitor, on colorectal cancer cell lines in vitro and in vivo. Int J Oncol 39:23-31, 2011 [PubMed: 21523318]

31. Gilmartin AG, Bleam MR, Groy A, et al.: GSK1120212 (JTP-74057) is an inhibitor of MEK activity and activation with favorable pharmacokinetic properties for sustained in vivo pathway inhibition. Clin Cancer Res 17:989-1000, 2011 [PubMed: 21245089]

32. Falchook GS, Lewis KD, Infante JR, et al.: Activity of the oral MEK inhibitor trametinib in patients with advanced melanoma: a phase 1 dose-escalation trial. Lancet Oncol 13:782-9, 2012 [PubMed: 22805292]

33. Hoeflich KP, Merchant M, Orr C, et al.: Intermittent administration of MEK inhibitor GDC-0973 plus PI3K inhibitor GDC-0941 triggers robust apoptosis and tumor growth inhibition. Cancer Res 72:210-9, 2012 [PubMed: 22084396]

34. Stones CJ, Kim JE, Joseph WR, et al.: Comparison of responses of human melanoma cell lines to MEK and BRAF inhibitors. Front Genet 4:66, 2013 [PubMed: 23658559]

35. Solit DB, Garraway LA, Pratilas CA, et al.: BRAF mutation predicts sensitivity to MEK inhibition. Nature 439:358-62, 2006 [PubMed: 16273091]

36. Rinehart J, Adjei AA, Lorusso PM, et al.: Multicenter phase II study of the oral MEK inhibitor, CI-1040, in patients with advanced non-small-cell lung, breast, colon, and pancreatic cancer. J Clin Oncol 22:4456-62, 2004 [PubMed: 15483017]

37. LoRusso PM, Krishnamurthi SS, Rinehart JJ, et al.: Phase I pharmacokinetic and pharmacodynamic study of the oral MAPK/ERK kinase inhibitor PD-0325901 in patients with advanced cancers. Clin Cancer Res 16:1924-37, 2010 [PubMed: 20215549]

38. Burgess MR, Hwang E, Firestone AJ, et al.: Preclinical efficacy of MEK inhibition in Nras-mutant AML. Blood 124:3947-55, 2014 [PubMed: 25361812]

39. Borthakur G, Foran J, Kadia T, et al. GSK1120212, a MEK1/MEK2 inhibitor demonstrates acceptable tolerability and preliminary activity in a dose rising trial in subjects with AML and other hematologic malignancies. Blood 2010;116:3281.

40. Britten CD: PI3K and MEK inhibitor combinations: examining the evidence in selected tumor types. Cancer Chemother Pharmacol 71:1395-409, 2013 [PubMed: 23443307]

41. Hoeflich KP, O'Brien C, Boyd Z, et al.: In vivo antitumor activity of MEK and phosphatidylinositol 3-kinase inhibitors in basal-like breast cancer models. Clin Cancer Res 15:4649-64, 2009 [PubMed: 19567590] 
42. Bedard PL, Tabernero J, Janku F, et al.: Ph lb dose escalation study of oral pan-PI3K inhibitor buparlisib (BKM120) with oral MEK1/2 inhibitor trametinib (GSK1120212) in patients with advanced solid tumours. Clin Cancer Res, 2014

43. Tolcher AW, Patnaik A, Papadopoulos KP, et al.: Phase I study of the MEK inhibitor trametinib in combination with the AKT inhibitor afuresertib in patients with solid tumors and multiple myeloma. Cancer Chemother Pharmacol 75:183-9, 2015 [PubMed: 25417902]

44. Tolcher AW, Bendell JC, Papadopoulos KP, et al.: A phase IB trial of the oral MEK inhibitor trametinib (GSK1120212) in combination with everolimus in patients with advanced solid tumors. Ann Oncol 26:58-64, 2015 [PubMed: 25344362]

45. Infante JR, Papadopoulos KP, Bendell JC, et al.: A phase 1b study of trametinib, an oral Mitogenactivated protein kinase kinase (MEK) inhibitor, in combination with gemcitabine in advanced solid tumours. Eur J Cancer 49:2077-85, 2013 [PubMed: 23583440]

46. Infante JR, Somer BG, Park JO, et al.: A randomised, double-blind, placebo-controlled trial of trametinib, an oral MEK inhibitor, in combination with gemcitabine for patients with untreated metastatic adenocarcinoma of the pancreas. Eur J Cancer 50:2072-81, 2014 [PubMed: 24915778]

47. Kim KB, Kefford R, Pavlick AC, et al.: Phase II study of the MEK1/MEK2 inhibitor Trametinib in patients with metastatic BRAF-mutant cutaneous melanoma previously treated with or without a BRAF inhibitor. J Clin Oncol 31:482-9, 2013 [PubMed: 23248257]

48. Johnson DB, Flaherty KT, Weber JS, et al.: Combined BRAF (Dabrafenib) and MEK inhibition (Trametinib) in patients with BRAFV600-mutant melanoma experiencing progression with singleagent BRAF inhibitor. J Clin Oncol 32:3697-704, 2014 [PubMed: 25287827] * Poor activity of dabrafenib and trametinib combination therapy after progression on BRAF inhibitor monotherapy, especially for patients with short ( $<6$ mos) initial benefit from the single agent BRAF inhibitor.

49. Hodis E, Watson IR, Kryukov GV, et al.: A landscape of driver mutations in melanoma. Cell 150:251-63, 2012 [PubMed: 22817889]

50. Ascierto PA, Schadendorf D, Berking C, et al.: MEK162 for patients with advanced melanoma harbouring NRAS or Val600 BRAF mutations: a non-randomised, open-label phase 2 study. Lancet Oncol 14:249-56, 2013 [PubMed: 23414587] • First MEK inhibitor study to show consistent activity in NRAS mutant melanoma.

51. Coupe N, Corrie P, Hategan M, et al.: PACMEL: A phase 1 dose escalation trial of trametinib (GSK1120212) in combination with paclitaxel. Eur J Cancer, 2014

52. Posch C, Moslehi H, Feeney L, et al.: Combined targeting of MEK and PI3K/mTOR effector pathways is necessary to effectively inhibit NRAS mutant melanoma in vitro and in vivo. Proc Natl Acad Sci U S A 110:4015-20, 2013 [PubMed: 23431193]

53. Chappell WH, Steelman LS, Long JM, et al.: Ras/Raf/MEK/ERK and PI3K/PTEN/Akt/mTOR inhibitors: rationale and importance to inhibiting these pathways in human health. Oncotarget 2:135-64, 2011 [PubMed: 21411864]

54. Rebecca VW, Alicea GM, Paraiso KH, et al.: Vertical inhibition of the MAPK pathway enhances therapeutic responses in NRAS-mutant melanoma. Pigment Cell Melanoma Res 27:1154-8, 2014 [PubMed: 25130256]

55. Ranzani M, Alifrangis C, Perna D, et al.: BRAF/NRAS wild-type melanoma, NF1 status and sensitivity to trametinib. Pigment Cell Melanoma Res 28:117-9, 2015 [PubMed: 25243813]

56. Nissan MH, Pratilas CA, Jones AM, et al.: Loss of NF1 in cutaneous melanoma is associated with RAS activation and MEK dependence. Cancer Res 74:2340-50, 2014 [PubMed: 24576830]

57. Bowyer SE, Rao AD, Lyle M, et al.: Activity of trametinib in K601E and L597Q BRAF mutationpositive metastatic melanoma. Melanoma Res 24:504-8, 2014 [PubMed: 24933606]

58. Dahlman KB, Xia J, Hutchinson K, et al.: BRAF(L597) mutations in melanoma are associated with sensitivity to MEK inhibitors. Cancer Discov 2:791-7, 2012 [PubMed: 22798288]

59. Larkin J, Ascierto PA, Dreno B, et al.: Combined vemurafenib and cobimetinib in BRAF-mutated melanoma. N Engl J Med 371:1867-76, 2014 [PubMed: 25265494]

60. Carvajal RD, Sosman JA, Quevedo JF, et al.: Effect of selumetinib vs chemotherapy on progression-free survival in uveal melanoma: a randomized clinical trial. JAMA 311:2397-405, 2014 [PubMed: 24938562] 
61. Hatzivassiliou G, Haling JR, Chen H, et al.: Mechanism of MEK inhibition determines efficacy in mutant KRAS- versus BRAF-driven cancers. Nature 501:232-6, 2013 [PubMed: 23934108]

62. Schadendorf D, Amonkar MM, Milhem M, et al.: Functional and symptom impact of trametinib versus chemotherapy in BRAF V600E advanced or metastatic melanoma: quality-of-life analyses of the METRIC study. Ann Oncol 25:700-6, 2014 [PubMed: 24504441]

63. Su F, Viros A, Milagre C, et al.: RAS mutations in cutaneous squamous-cell carcinomas in patients treated with BRAF inhibitors. N Engl J Med 366:207-15, 2012 [PubMed: 22256804]

64. Lee CI, Menzies AM, Haydu LE, et al.: Features and management of pyrexia with combined dabrafenib and trametinib in metastatic melanoma. Melanoma Res 24:468-74, 2014 [PubMed: 25054915]

65. Zimmer L, Barlesi F, Martinez-Garcia M, et al.: Phase I expansion and pharmacodynamic study of the oral MEK inhibitor RO4987655 (CH4987655) in selected patients with advanced cancer with RAS-RAF mutations. Clin Cancer Res 20:4251-61, 2014 [PubMed: 24947927]

66. Loaiza-Bonilla A, Clayton E, Furth E, et al.: Dramatic response to dabrafenib and trametinib combination in a BRAF V600E-mutated cholangiocarcinoma: implementation of a molecular tumour board and next-generation sequencing for personalized medicine. Ecancermedicalscience 8:479, 2014 [PubMed: 25435907]

67. Wolchok JD, Kluger H, Callahan MK, et al.: Nivolumab plus ipilimumab in advanced melanoma. N Engl J Med 369:122-33, 2013 [PubMed: 23724867]

68. Hu-Lieskovan S, Robert L, Homet Moreno B, et al.: Combining targeted therapy with immunotherapy in BRAF-mutant melanoma: promise and challenges. J Clin Oncol 32:2248-54, 2014 [PubMed: 24958825]

69. Berthon C, Driss V, Liu J, et al.: In acute myeloid leukemia, B7-H1 (PD-L1) protection of blasts from cytotoxic $\mathrm{T}$ cells is induced by TLR ligands and interferon-gamma and can be reversed using MEK inhibitors. Cancer Immunol Immunother 59:1839-49, 2010 [PubMed: 20814675]

70. Ott PA, Bhardwaj N: Impact of MAPK Pathway Activation in BRAF(V600) Melanoma on T Cell and Dendritic Cell Function. Front Immunol 4:346, 2013 [PubMed: 24194739]

71. Ribas A, Hodi FS, Callahan M, et al.: Hepatotoxicity with combination of vemurafenib and ipilimumab. N Engl J Med 368:1365-6, 2013 [PubMed: 23550685]

72. Puzanov ICM, Linette GP, Patel SP, Luke JJ, et al. : Phase 1 study of the BRAF inhibitor dabrafenib (D) with or without the MEK inhibitor trametinib (T) in combination with ipilimumab (Ipi) for V600E/K mutation-positive unresectable or metastatic melanoma (MM). J Clin Oncol 2014;32(15_suppl):2511. 
Drug Summary Box

\begin{tabular}{|l|l|}
\hline Drug name & Tramenitib \\
\hline Phase & III \\
\hline Indication & $B R A F^{\mathrm{V} 600}$ mutant metastatic melanoma \\
\hline Pharmacology & $\begin{array}{l}\text { Inhibitor of MEK 1 and 2, resulting in growth factor-mediated inhibition of cell } \\
\text { signalling and proliferation }\end{array}$ \\
\hline Route of administration & Oral \\
\hline Chemical structure & $\begin{array}{l}\text { N-(3-\{3-cyclopropyl-5-[(2-fluoro-4-iodophenyl)amino]-6,8-dimethyl-2,4,7- } \\
\text { trioxo-3,4,6,7-tetrahydropyrido[4,3-d]pyrimidin-1(2H)-yl }\} \text { phenyl) acetamide }\end{array}$ \\
\hline Pivotal trial(s) & Phase I [15, 26, 32], Phase II [15, 47], Phase III [14, 18, 19] \\
\hline
\end{tabular}


Table 1:

Clinical Trials of Trametinib in melanoma

\begin{tabular}{|c|c|c|c|c|c|c|c|c|}
\hline Trial & Phase & Target & Drug & Stu & y population & PFS & $\mathbf{R R}$ & Remarks \\
\hline $\begin{array}{l}\text { Infante et.al } \\
\text { [26] }\end{array}$ & I & MEK & Trametinib & $\begin{array}{l}\text { Advanced } \\
\text { solid tumors } \\
\mathrm{N}=206\end{array}$ & $\begin{array}{l}\text { Pancreatic }(n=26) \\
\text { Colorectal }(n=28) \\
\text { NSCLC }(n=30) \\
\text { Melanoma }(n=97) \\
\text { Others }(n=25)\end{array}$ & - & $10 \%$ & $\begin{array}{l}\text { MTD }=3 \mathrm{mg} \text { daily } \\
\mathrm{RP} 2 \mathrm{D}=2 \mathrm{mg} \text { daily }\end{array}$ \\
\hline $\begin{array}{l}\text { Falchook } \\
\text { et.al [32] }\end{array}$ & I & MEK & Trametinib & $\begin{array}{l}\text { Metastatic } \\
\text { Melanoma } \\
\mathrm{N}=97\end{array}$ & $\begin{array}{l}\text { BRAF mutant }(\mathrm{n}=36) \\
\text { BRAFi naïve }(\mathrm{n}=30) \\
\text { Prior BRAFi }(\mathrm{n}=6) \\
\text { BRAF wild }(\mathrm{n}=39) \\
\text { BRAF unknown }(\mathrm{n}=6) \\
\text { NRAS mutant }(\mathrm{n}=7) \\
\text { Uveal melanoma } \\
(\mathrm{n}=16)\end{array}$ & $\begin{array}{l}5.7 \\
\text { NA } \\
2 \\
\text { NA } \\
\text { NA } \\
1.8\end{array}$ & $\begin{array}{l}40 \% \\
\text { NA } \\
10 \% \\
0 \% \\
0 \% \\
0 \%\end{array}$ & $\begin{array}{l}\text { Concurrent BRAFV600 } \\
\text { WT/NRAS WT }(\mathrm{n}=20) \\
\text { had a trend of higher } \\
\text { RR }(20 \%) \text { than } \\
\text { BRAFV600WT/ } \\
\text { NRAS-mutant patients }\end{array}$ \\
\hline $\begin{array}{l}\text { Kim et.al } \\
{[47]}\end{array}$ & II & MEK & Trametinib & $\begin{array}{l}\text { BRAF mutant } \\
\text { Metastatic } \\
\text { N=97 }\end{array}$ & $\begin{array}{l}\text { BRAFi therapy }(\mathrm{n}=40) \\
\text { BRAFi naïve }(\mathrm{n}=57)\end{array}$ & $\begin{array}{l}1.8 \\
4\end{array}$ & $\begin{array}{l}0 \% \\
25 \%\end{array}$ & $\begin{array}{l}\text { stable disease }=28 \% \\
\text { stable disease }=51 \%\end{array}$ \\
\hline $\begin{array}{l}\text { Flaherty } \\
\text { et.al [14] }\end{array}$ & III & MEK & $\begin{array}{l}\text { Trametinib vs. } \\
\text { Chemo }\end{array}$ & $\begin{array}{l}\text { BRAF mutant } \\
\text { Metastatic } \\
\mathrm{N}=322\end{array}$ & $\begin{array}{l}\text { Trametinib }(n=214) \\
\text { Chemotherapy }(n=108)\end{array}$ & $\begin{array}{l}4.8 \\
1.5\end{array}$ & $\begin{array}{l}22 \% \\
8 \%\end{array}$ & $\begin{array}{l}6 \text { month OS }=81 \% \text { vs, } \\
67 \% \\
\text { stable disease }=56 \% \\
\text { vs. } 31 \%\end{array}$ \\
\hline $\begin{array}{l}\text { Flaherty } \\
\text { et.al [15] }\end{array}$ & $\mathrm{I} / \mathrm{II}$ & $\begin{array}{l}\text { BRAF } \\
\text { MEK }\end{array}$ & $\begin{array}{l}\text { Dabrafenib/ } \\
\text { Trametinib }\end{array}$ & $\begin{array}{l}\text { BRAF V600 } \\
\text { mutant } \\
\text { Metastatic } \\
\mathrm{N}=162\end{array}$ & $\begin{array}{l}\text { DT } 150 / 2(\mathrm{n}=54) \\
\text { DT } 150 / 1(\mathrm{n}=54 \\
\text { D150 }(\mathrm{n}=54)\end{array}$ & $\begin{array}{l}9.4 \\
9.2 \\
5.8\end{array}$ & $\begin{array}{l}76 \% \\
50 \% \\
54 \%\end{array}$ & \\
\hline $\begin{array}{l}\text { Long et.al } \\
{[18]}\end{array}$ & III & $\begin{array}{l}\text { BRAF } \\
\text { MEK }\end{array}$ & $\begin{array}{l}\text { Dabrafenib/ } \\
\text { Trametinib vs. } \\
\text { Dabrafenib }\end{array}$ & $\begin{array}{l}\text { BRAF } \\
\text { V600E/K } \\
\mathrm{N}=423\end{array}$ & $\begin{array}{l}\mathrm{DT}(\mathrm{n}=211) \\
\mathrm{D}(\mathrm{n}=212)\end{array}$ & $\begin{array}{l}9.3 \\
8.8\end{array}$ & $\begin{array}{l}67 \% \\
55 \%\end{array}$ & \\
\hline $\begin{array}{l}\text { Robert et.al } \\
{[19]}\end{array}$ & III & $\begin{array}{l}\text { BRAF } \\
\text { MEK }\end{array}$ & $\begin{array}{l}\text { Dabrafenib/ } \\
\text { Trametinib vs. } \\
\text { Vemurafenib }\end{array}$ & $\begin{array}{l}\text { BRAF } \\
\text { V600E/K } \\
\mathrm{N}=604\end{array}$ & $\begin{array}{l}\text { DT }(n=352) \\
\text { V }(n=352)\end{array}$ & $\begin{array}{l}11.4 \\
7.3\end{array}$ & $\begin{array}{l}64 \% \\
51 \%\end{array}$ & $\begin{array}{l}12 \text { month OS } \\
72 \% \text { vs. } 67 \%\end{array}$ \\
\hline
\end{tabular}

PFS- progression free survival (in months); RR- response rates; NSCLC- Non small cell lung cancer; MTD-Maximum Tolerated Dose; RP2D-

Recommended phase 2 dose; WT- wild type; BRAFi - BRAF inhibitor; n- number of patients; OS- overall survival 
Table 2:

\begin{tabular}{|c|c|c|c|}
\hline \multirow[t]{2}{*}{ Adverse Event } & \multicolumn{3}{|c|}{ Frequency of toxicity (\%) -All grade (grade 3 and 4) } \\
\hline & Infante et.al [26] & Falchook et.al [32] & Kim et.al [47] \\
\hline Rash/Dermatitis Acneiform & $80(8)$ & $92(8) / 85(8)$ & $75(9)$ \\
\hline Diarrhea & $42(<1)$ & $42(0)$ & $52(4)$ \\
\hline Fatigue & $33(4)$ & $35(4)$ & $26(2)$ \\
\hline Peripheral edema & $29(<1)$ & $35(0)$ & $29(3)$ \\
\hline Nausea & $28(0)$ & $21(0)$ & $30(0)$ \\
\hline Vomiting & $17(1)$ & $8(0)$ & $18(0)$ \\
\hline Pruritis & $14(0)$ & $15(0)$ & $27(1)$ \\
\hline Dry skin & $18(0)$ & - & $22(0)$ \\
\hline Decreased appetite & $10(<1)$ & - & $11(1)$ \\
\hline Ocular toxicity & $15(<1)$ & - & - \\
\hline Mucosal inflammation & $7(0)$ & $4(0)$ & - \\
\hline Constipation & $5(0)$ & - & $14(0)$ \\
\hline Decreased Ejection fraction & $8(0)$ & - & - \\
\hline Periorbital edema & $5(0)$ & - & - \\
\hline Thrombocytopenia & $5(<1)$ & - & - \\
\hline Dry mouth & $5(0)$ & - & $11(0)$ \\
\hline Dry skin & - & $31(0)$ & - \\
\hline
\end{tabular}


Table 3:

Adverse events with combination therapy with Trametinib

\begin{tabular}{|c|c|c|c|}
\hline \multirow[t]{3}{*}{ Adverse event } & \multicolumn{3}{|c|}{ Trametinib+ Dabrafenib } \\
\hline & \multicolumn{3}{|c|}{ Frequency of toxicity $(\%)$-All grade (grade 3) } \\
\hline & Robert et.al [19] & Long et.al [18] & Flaherty et.al [15] \\
\hline Pyrexia & $53(4)$ & $51(6)$ & $71(5)$ \\
\hline Fatigue & - & $35(2)$ & $53(4)$ \\
\hline Headache & - & $30(<1)$ & $29(0)$ \\
\hline Nausea & $35(<1)$ & $30(0)$ & $44(2)$ \\
\hline Chills & $31(1)$ & $30(0)$ & $58(2)$ \\
\hline Arthralgia & $24(1)$ & $24(<1)$ & $27(0)$ \\
\hline Diarrhea & $32(1)$ & $24(1)$ & $36(2)$ \\
\hline Rash & $22(1)$ & $23(0)$ & $27(0)$ \\
\hline Hypertension & - & $22(4)$ & $9(2)$ \\
\hline Vomiting & $29(1)$ & $20(1)$ & $40(2)$ \\
\hline Cough & - & $16(0)$ & $29(0)$ \\
\hline Peripheral edema & - & $14(<1)$ & $29(0)$ \\
\hline Pain in a limb & - & $14(1)$ & \\
\hline Decreased appetite & - & $11(<1)$ & $22(0)$ \\
\hline Abdominal pain & - & $11(1)$ & - \\
\hline Elevated ALT & - & $11(2)$ & - \\
\hline Elevated AST & - & $11(3)$ & - \\
\hline Elevated Alkaline phosphatase & - & & $9(0)$ \\
\hline Constipation & - & $11(<1)$ & $22(0)$ \\
\hline Myalgia & - & $11(<1)$ & $22(2)$ \\
\hline Asthenia & - & $10(<1)$ & - \\
\hline Dizziness & - & $10(0)$ & - \\
\hline Nasopharyngitis & - & $10(0)$ & - \\
\hline Back pain & - & $9(1)$ & - \\
\hline Dry skin & - & $9(0)$ & - \\
\hline Pruritis & - & $8(0)$ & - \\
\hline Alopecia & $6(0)$ & $7(0)$ & $5(0)$ \\
\hline Hand foot syndrome & $4(0)$ & $5(0)$ & - \\
\hline Hyperkeratosis & $4(0)$ & $3(0)$ & $9(0)$ \\
\hline Skin papilloma & $2(0)$ & $1(0)$ & $4(0)$ \\
\hline Night sweats & - & - & $24(0)$ \\
\hline Cutaneous SCC & $1(1)$ & $2(2)$ & $7(5)$ \\
\hline Decreased EF & $8(4)$ & $4(<1)$ & $9(0)$ \\
\hline Chorioretinopathy & $1(0)$ & $<1(0)$ & $2(2)$ \\
\hline Decreased Vision & & $2(0)$ & - \\
\hline
\end{tabular}




\begin{tabular}{|l|l|l|l|}
\hline Adverse event & \multicolumn{3}{|c|}{ Trametinib+ Dabrafenib } \\
\hline & \multicolumn{3}{|c|}{ Frequency of toxicity (\%) -All grade (grade 3) } \\
\hline & Robert et.al [19] & Long et.al [18] & Flaherty et.al [15] \\
\hline Dermatitis Acneiform & $6(0)$ & $8(0)$ & - \\
\hline Photosensitivity & $4(0)$ & - & - \\
\hline
\end{tabular}




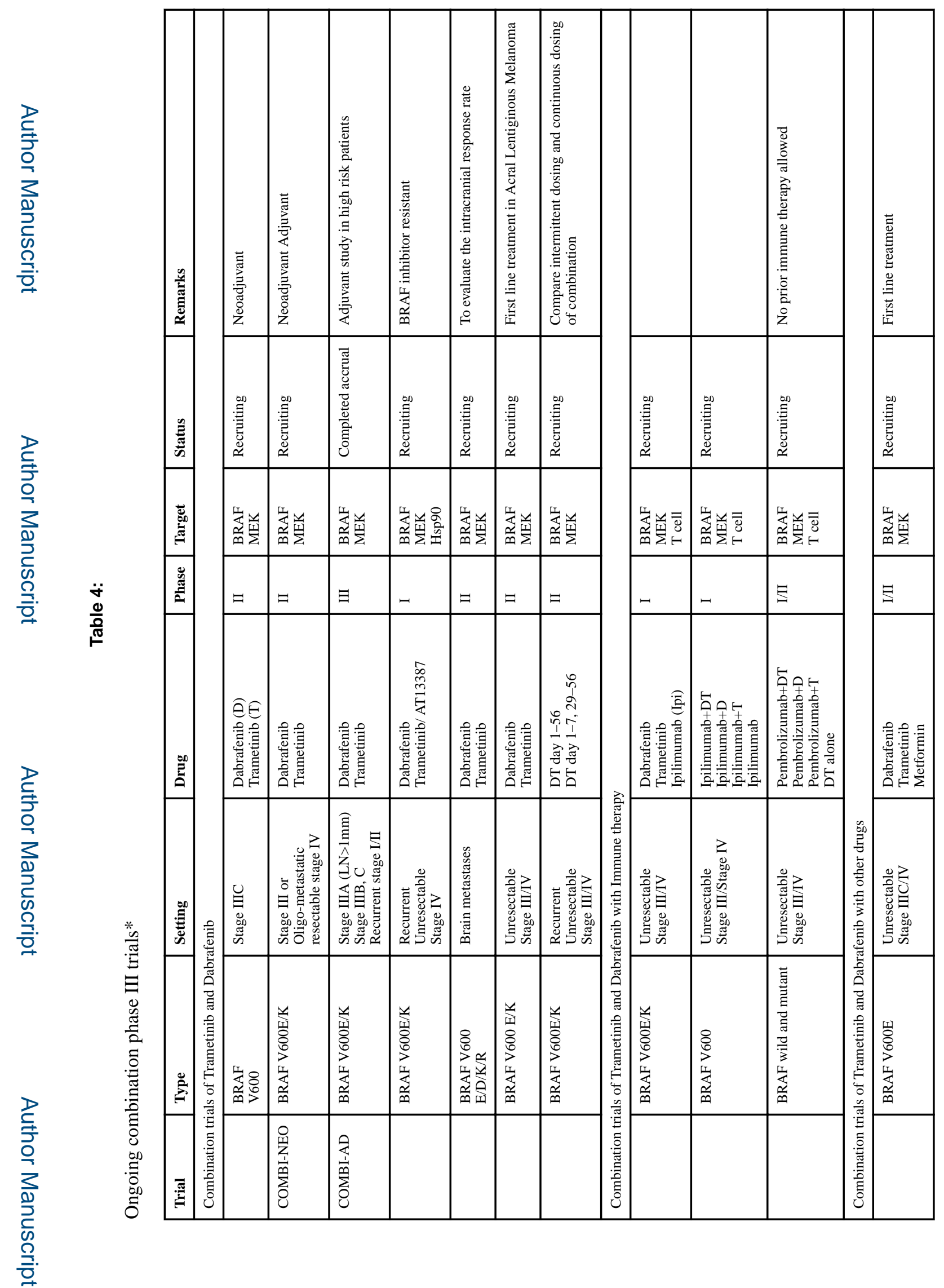

Expert Opin Biol Ther. Author manuscript; available in PMC 2019 August 06. 


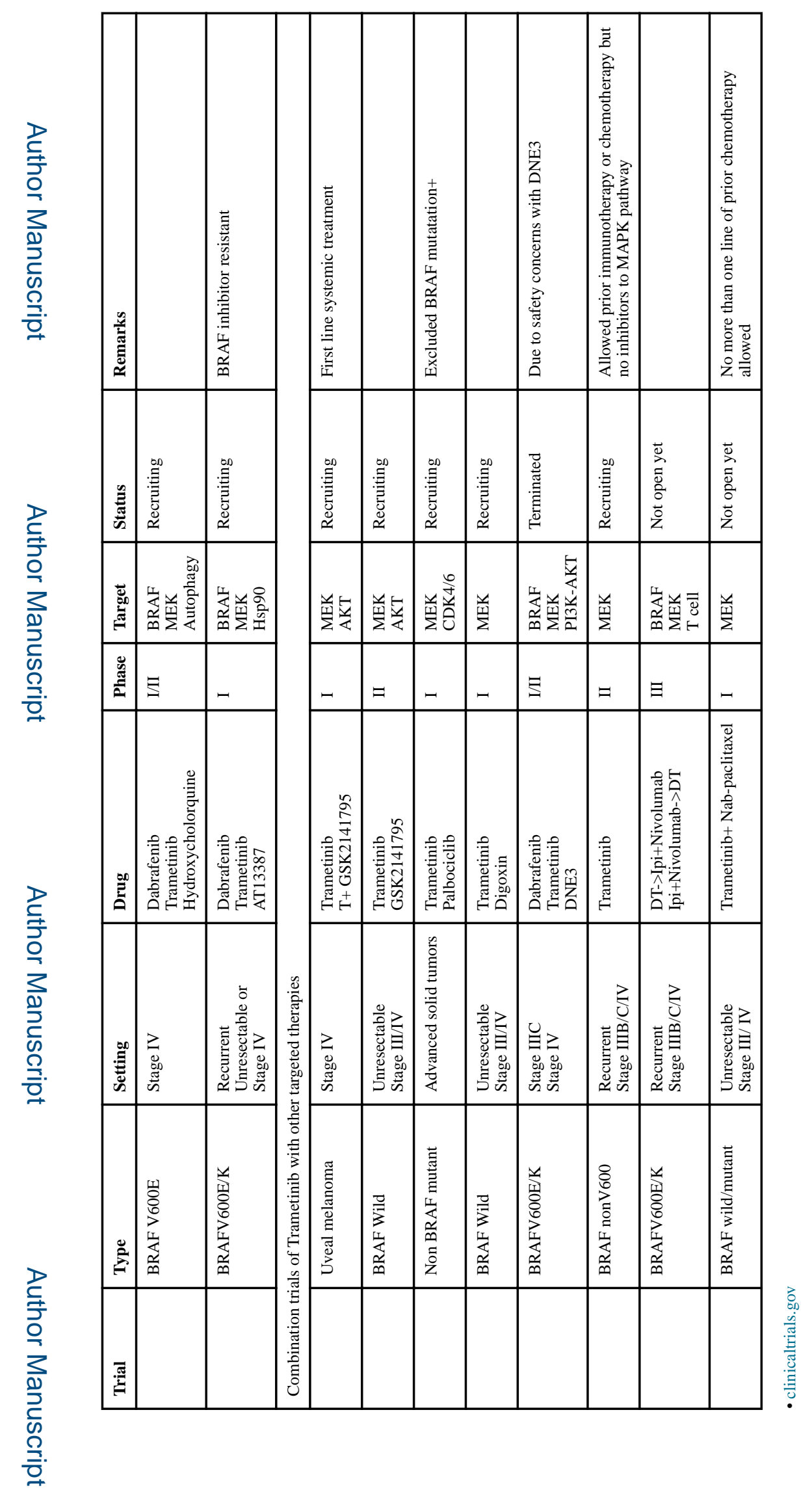

Expert Opin Biol Ther. Author manuscript; available in PMC 2019 August 06. 